Journal of Structural Heart Disease, May 2015,

Volume 1, Issue 1: 20-32

DOI: http://dx.doi.org/10.12945/j.jshd.2015.00009-14
Received: December 8, 2014 Accepted: December 15, 2014 Published online: May 2015

\title{
Balloon Aortic Valvuloplasty Patient Selection and Technical Considerations
}

\author{
Ted Feldman, MD, FESC, FACC, MSCAI', Mohammad Sarraf, MD, Wes Pedersen, MD, FACC, FSCAI \\ Evanston Hospital, NorthShore University Health System, Evanston, Illinois
}

NOTE: This manuscript includes videos. Not all PDF readers support video. For desktop computers we recommend using Adobe Acrobat Reader. To view videos within a PDF on an iPad we recommend viewing in ezPDF Reader or PDF Expert. On desktop computers you may view videos full screen by clicking on a video, right click on the video, then choose Full Screen Multimedia.

\begin{abstract}
BAV has had resurgence in association with the dissemination of TAVR. The lack of clear mortality benefit from BAV does not translate to lack of efficacy as a palliative therapy. BAV remains a useful bridge to surgical AVR or TAVR, and for symptom relief in patients who are not candidates for either AVR approach. It is also useful as a diagnostic test for patients with low gradient-low output AS, and for those with mixed pulmonary and aortic valvular disease. BAV is used commonly for TAVR pre dilatation, and this is sometimes helpful for annulus size assessment. Careful attention to balloon diameter selection and the details of technique are important for optimizing outcomes.

Copyright $\odot 2015$ Science International Corp.
\end{abstract}

\section{Key Words}

Balloon • Aortic • Valvuloplasty • General

\section{Introduction}

It is widely recognized that balloon aortic valvuloplasty balloon aortic valvuloplasty (BAV) does not contribute to an improvement in survival among nonsurgical or very high-risk patients with aortic stenosis. Unfortunately, the value of BAV as a palliative therapy has been overlooked in the shadow of this lack of mortality benefit. Clinical improvement after

ax +1 2037853346

E-Mail: jshd@scienceinternational.org

http://structuralheartdisease.org/
(C) 2015 Journal of Structural Heart Disease Published by Science International Corp. ISSN 2326-4004

Accessible online at: http://structuralheartdisease.org/
BAV occurs in the vast majority of patients. While in many this clinical improvement is short-lived, a majority of patients feel improved symptoms for as long as 1 year [1]. The utility of this therapy as a palliative treatment is seen best among patients, who truly have no other option [2]. For example, the extreme risk patient, who is a candidate for neither surgical nor transcatheter AVR may undergo BAV periodically for relief of symptoms. In our practice, there are patients, who have had roughly once yearly BAV procedures over a period of 2 or 3 years. This was, of course, more common before the availability of TAVR.

\section{Indications for Balloon Aortic Valvulolasty (BAV)}

Contemporary indications for balloon aortic valvuloplasty (BAV) in adults are framed by the use of transcatheter aortic valve replacement (TAVR) as the mainstay of therapy for patients with aortic stenosis (AS) who are high risk for surgical valve replacement (SAVR) [3]. BAV has clinical utility in several circumstances in current practice. The 2014 AHA/ ACC guideline for the management of patients with valvular heart disease characterizes this in a single level IIb (level of evidence C) recommendation, stating, "Percutaneous aortic balloon dilation may be considered

* Corresponding Author:

Ted Feldman, MD, FESC FACC MSCAI

Cardiology Division

Evanston Hospital

Walgreen Building 3rd Floor, Evanston, Illinois 60201 USA

Tel: +1 847 570-2250, Fax: +1 847 570-1865, E-Mail: tfeldman@tfeldman.org 


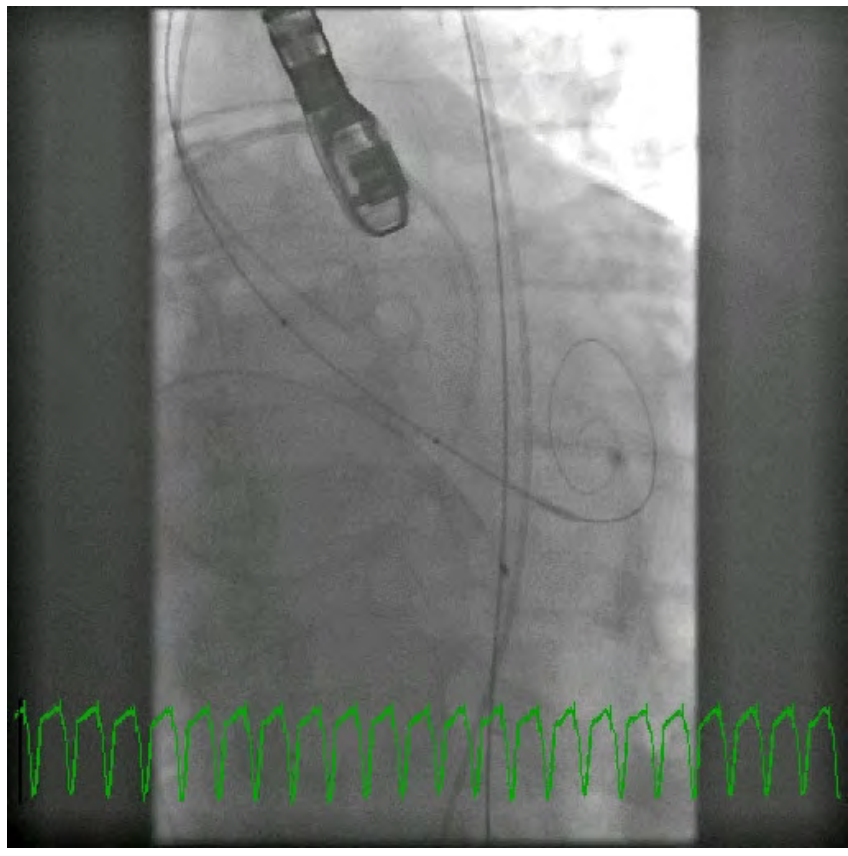

Figure 1. Hand injection of contrast during BAV with a $22 \mathrm{~mm}$ balloon showed locking of the balloon and no contrast regurgitation around the balloon.

as a bridge to surgical AVR or TAVR in patients with severe symptomatic AS" $[4,5]$. This defines an important role for BAV among patients who are unstable or in refractory heart failure prior to valve replacement with either SAVR or TAVR [6]. These patients may present with refractory heart failure or shock, and BAV can

Table 1. Indications for BAV

Bridge to SAVR

- Stabilize shock

- Treat severe CHF

- Bridge to TAVI

Symptom relief

- Stabilization while evaluation is undertaken

Diagnostic test: see how patient responds

- Low gradient/low output patient

- Mixed lung and valve disease

Therapy for "no-option" patient

- Anyone can undergo AVR

- Apical-descending aorta conduit is an option for some

Pre-op for non-cardiac surgery

Predilatation

- Sizing

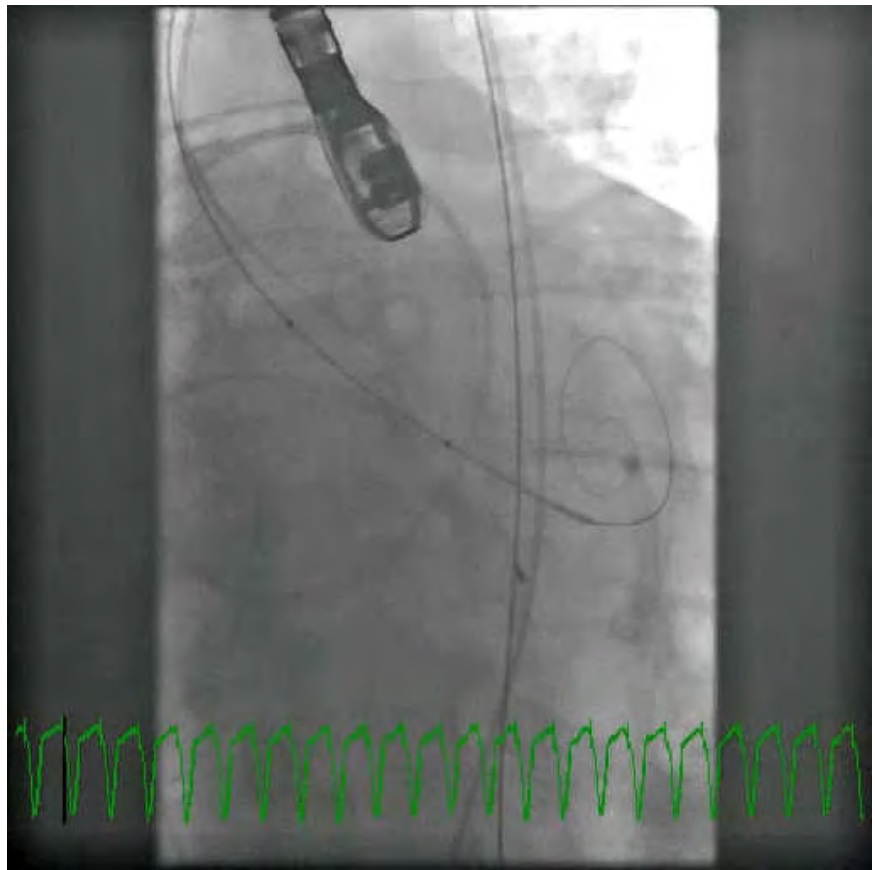

Figure 1 Video.

make them more manageable for the short term.

BAV is also used in several other clinical situations (Table 1). Another important utility of BAV is as a diagnostic test. Patients with low gradient and low output aortic stenosis with low left ventricular ejection fraction represent a frequent diagnostic conundrum. Prior to aortic valve replacement, BAV in this population may unmask the myocardial reserver for a more invasive valve replacement therapy. The best example of this patient group is those with mixed chronic lung and valvular heart disease. The degree to which they may improve after valve therapy is often uncertain, and those who have a favorable response to BAV may be expected to similarly benefit from aortic valve replacement.

A more controversial use of BAV is prior to non-cardiac surgery. While many patients with severe aortic stenosis can undergo non-cardiac surgery when special care is taken to manage their hemodynamic situation, there are clearly patients, who have no reserve for whom management during non-cardiac surgery is challenging. The patient, who presents with an absolute aortic valve area less than $0.5 \mathrm{~cm}^{2}$, or those with low cardiac output, very high pulmonary or pul- 


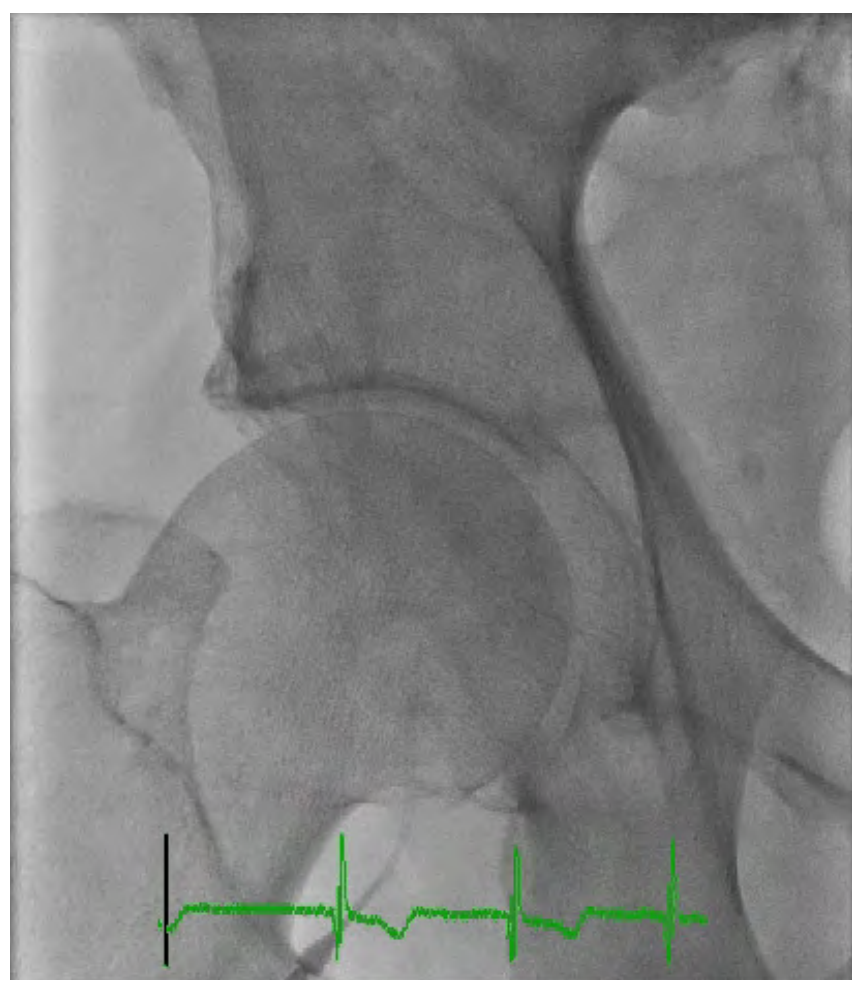

Figure 2. Micropuncture contrast injection after fluoro guided femoral access to ensure sheath insertion in a non-calcified segment of the common femoral artery.

monary wedge pressures, or refractory symptomatic heart failure, may be stabilized enough by BAV to make non-cardiac surgery more tolerable for both the patient and the Anesthesia Team [7].

Recently, the major use of BAV has been for predilatation during TAVR procedures. While the need for predilatation can be argued for some patient groups and for many average TAVR procedures, another utility of BAV for TAVR is to help with valve annulus sizing or choice of prosthesis size [8]. When predilatation with a balloon matched to the expected annulus size yields a sealing of the annulus evidenced by contrast injection during the balloon inflation, greater confidence can be found for a TAVR valve with the frame corresponding to the balloon size. Conversely, when the balloon will not lock in the valve, and a contrast injection during balloon inflation results in clear contrast regurgitation into the left ventricle, the balloon presents an undersized diameter for a given valve annulus.

Special care must be taken to be sure that the ful-

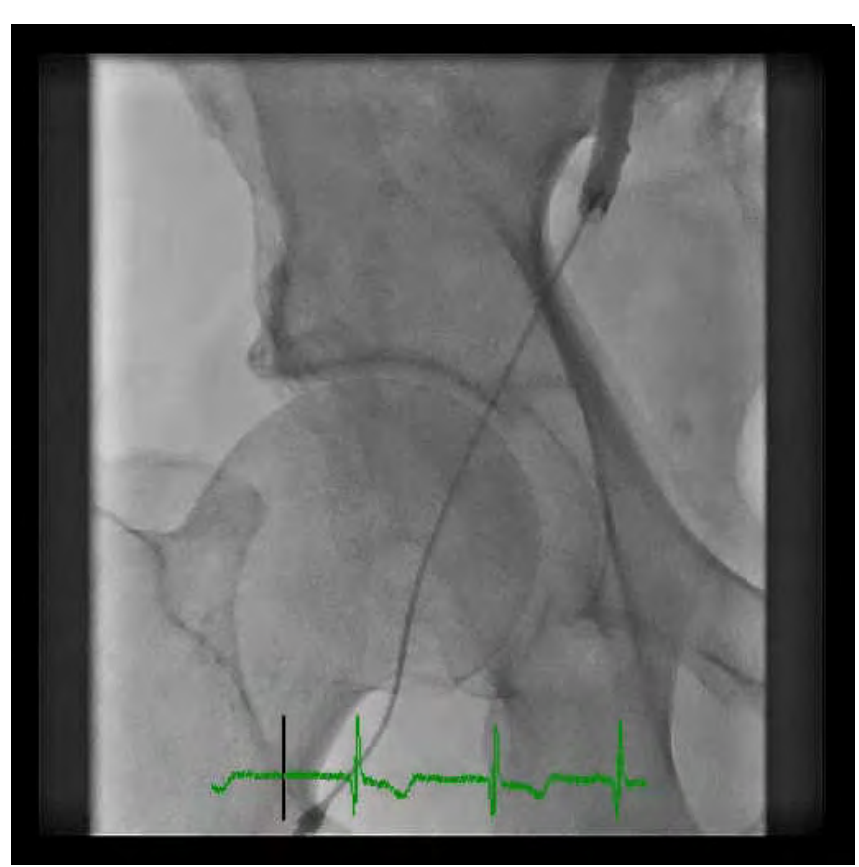

Figure 2 Video.

ly inflated predilatation balloon size measurement is accurate. Many balloons are manufactured with some variability in the technical specification. In addition, hand inflation using a large syringe typically results in under-filling of the balloon, and it is likely in that setting that the balloon will not achieve its nominal diameter. Two methods to insure correct and full inflation include either use of a volume driven inflation with an inflation device, or the addition of a side syringe and a high pressure stopcock to the larger hand inflation syringe.

BAV can be used as an aid to sizing for TAVR [9]. It is not uncommon to have ambiguity for the selection of TAVR device size, even with CT annulus measurements. This problem results when patients are truly on the borderline between valve prosthesis sizes based simply on measurements, and is exacerbated by the challenges of heavily calcified leaflets or left ventricular outflow tract, and the underappreciated problem of suboptimal CT scan images for analysis. One method favored by some operators to help resolve 


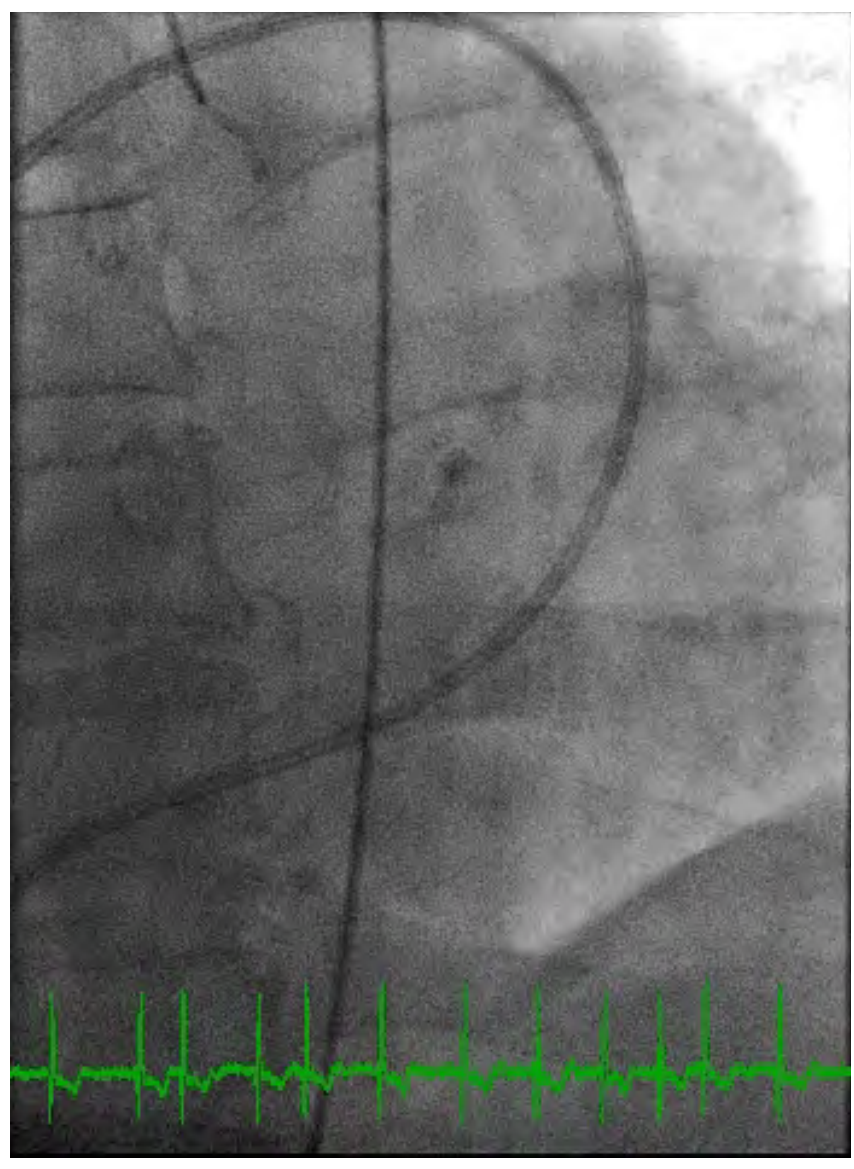

Figure 3. After arterial access is obtained, the valve is crossed using an AL1 diagnostic catheter and a straight tipped guide wire.

ambiguity when TAVR device sizing is problematic is to inject contrast in the aortic root during the BAV for TAVR predilatation. A balloon size is typically selected to approximate the short axis CT diameter of the valve. The short axis dimension of the annulus can also be ascertained from the typical transthoracic or transesophageal log axis echo.

The balloon is inflated and contrast is injected into the aortic root at the peak of balloon inflation (Figure 1). CT measurements prior to planned TAVR were borderline for a $23-\mathrm{mm}$ vs. a $26-\mathrm{mm}$ Edwards S3 implant. Hand injection of contrast during BAV with a 22-mm balloon showed locking of the balloon and no contrast regurgitation around the balloon. A 23-mm valve was implanted with a good result, including minimal paravalvular leak. The use of hand injections or various forms of power injections is

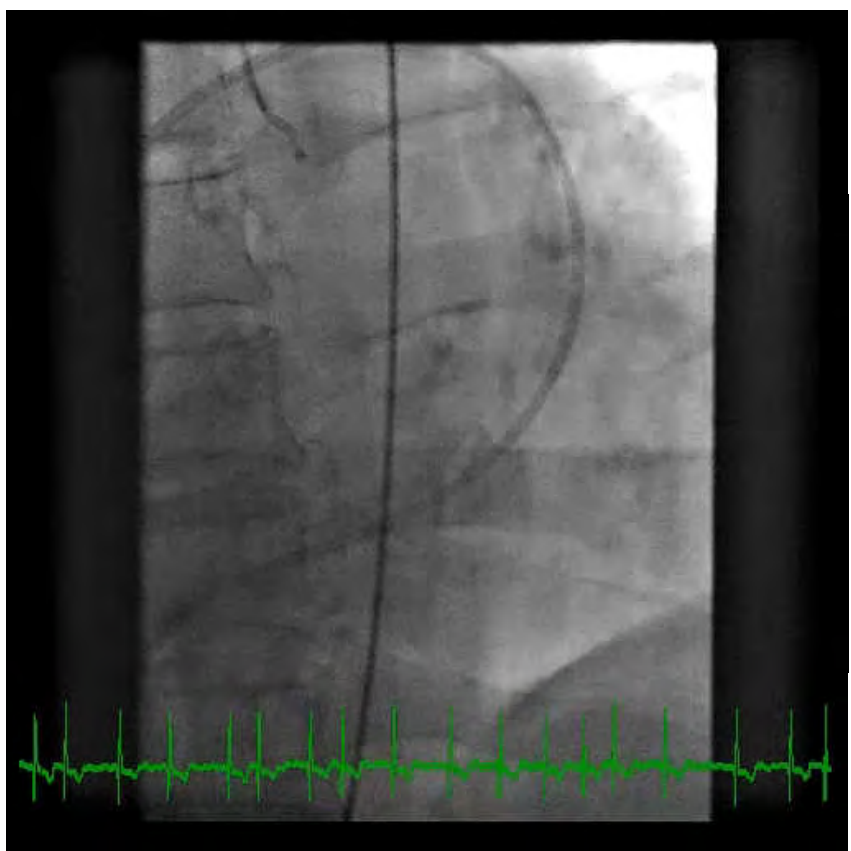

Figure 3 Video.

completely non-standardized. A caveat is that the tip of the pigtail used for injection may be trapped between the balloon and the aortic wall, especially if the sinotubular junction is small in diameter, and a power injection may result in a dissection of the aortic root. During contrast injections it is often difficult to assess whether there is significant contrast regurgitation around the balloon. Generally little or no contrast regurgitation into the left ventricle especially when associated with a balloon that locks into the native aortic anulus during inflation suggests that a valve prosthesis frame of about that diameter will be successful.

\section{BAV Techniques}

\section{Retrograde BAV}

The technique retrograde BAV was described initially for pediatric patients in 1985 and first reported in adult patients with degenerative calcific aortic stenosis in 1986. The technique was largely unchanged for two decades. More recently, several advances have contributed to the predictability of the procedure and its practically [10]. Balloons for BAV 


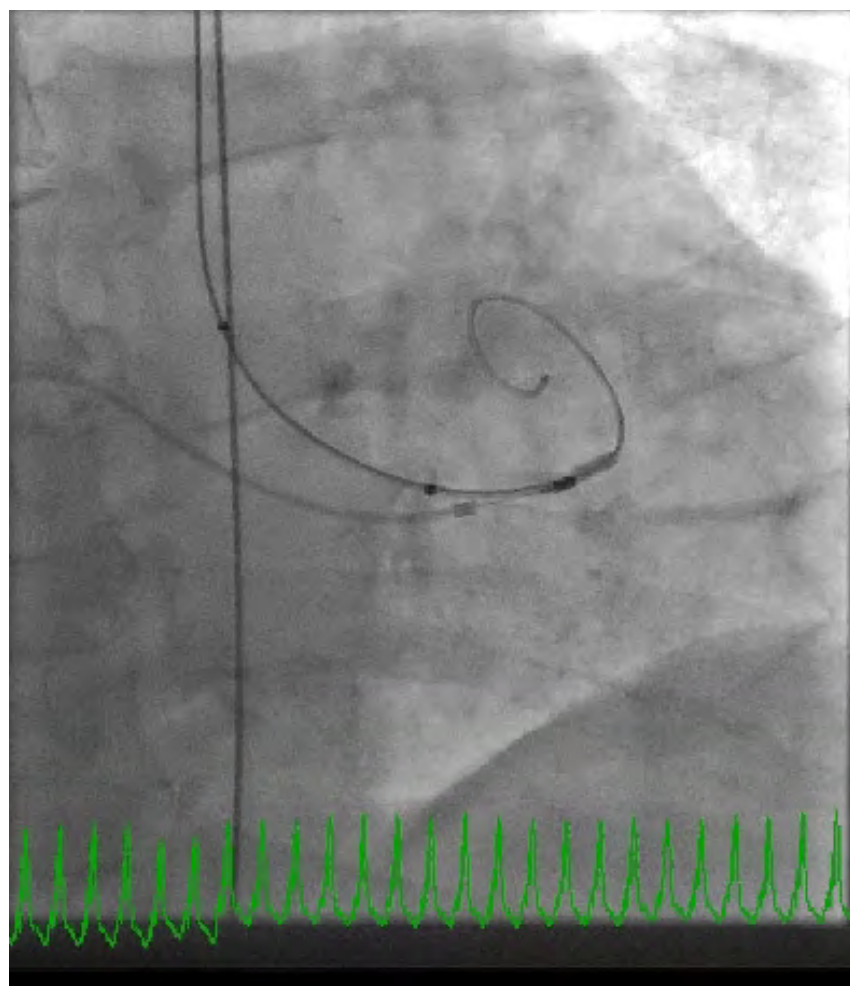

Figure 4. Rapid right ventricular pacing to cause hypotension, at a heart rate between 170 and 200 beats per minute, is initiated and when the blood pressure falls, the valvuloplasty balloon is inflated.

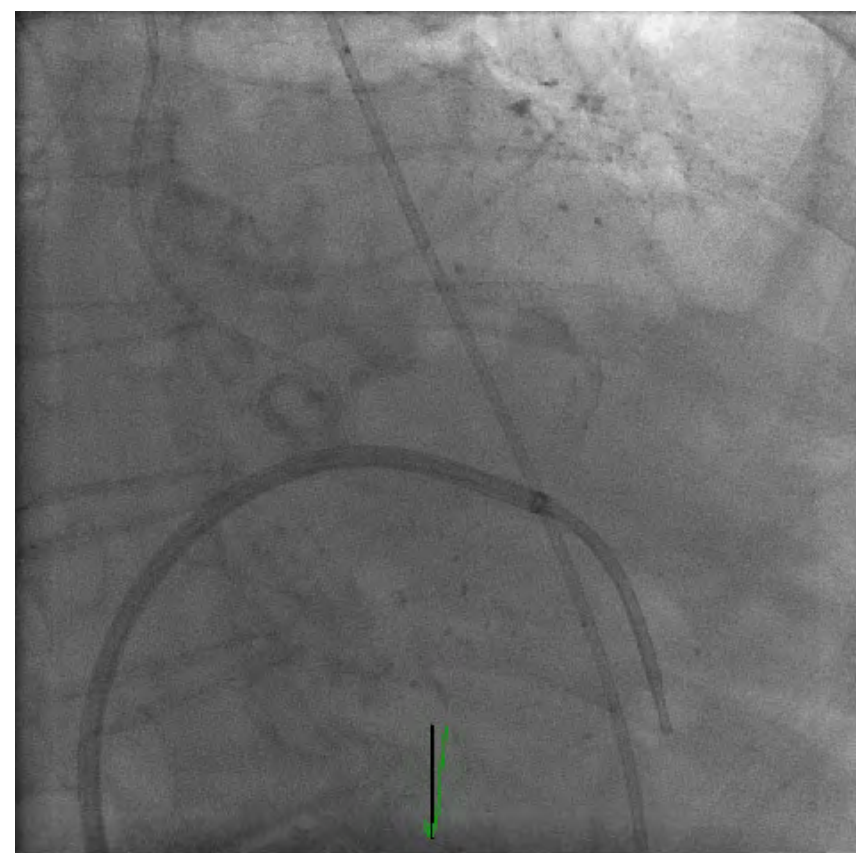

Figure 5. A 7-French single-lumen balloon catheter is inflated in the left atrium and with counterclockwise rotation of a standard Mullins sheath the balloon tip catheter is floated across the mitral valve.

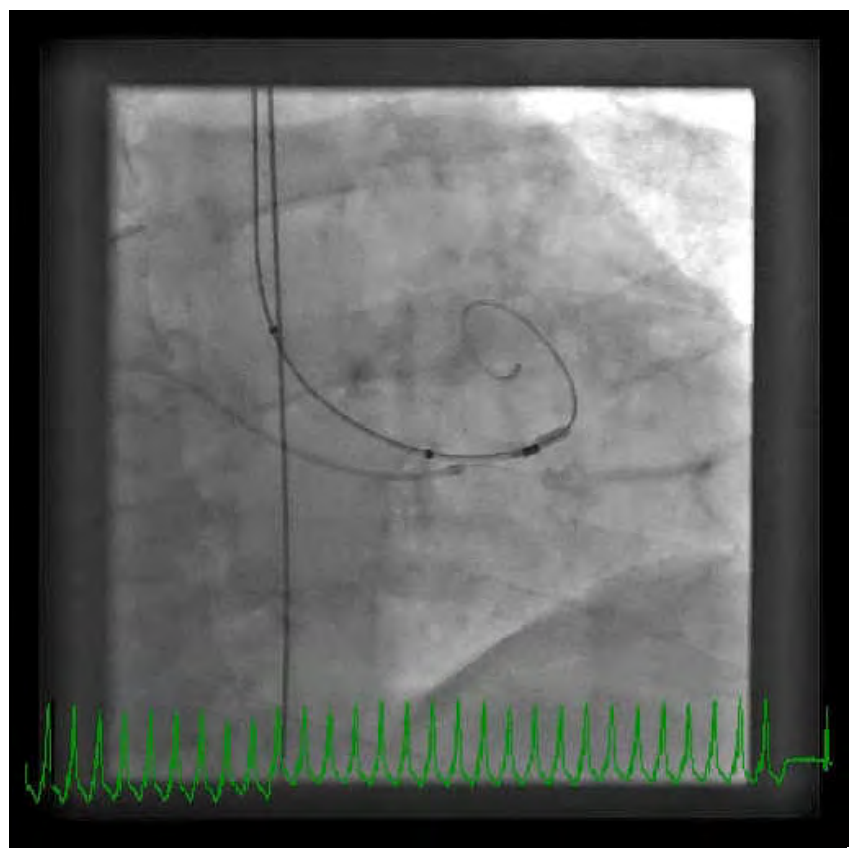

Figure 4 Video.

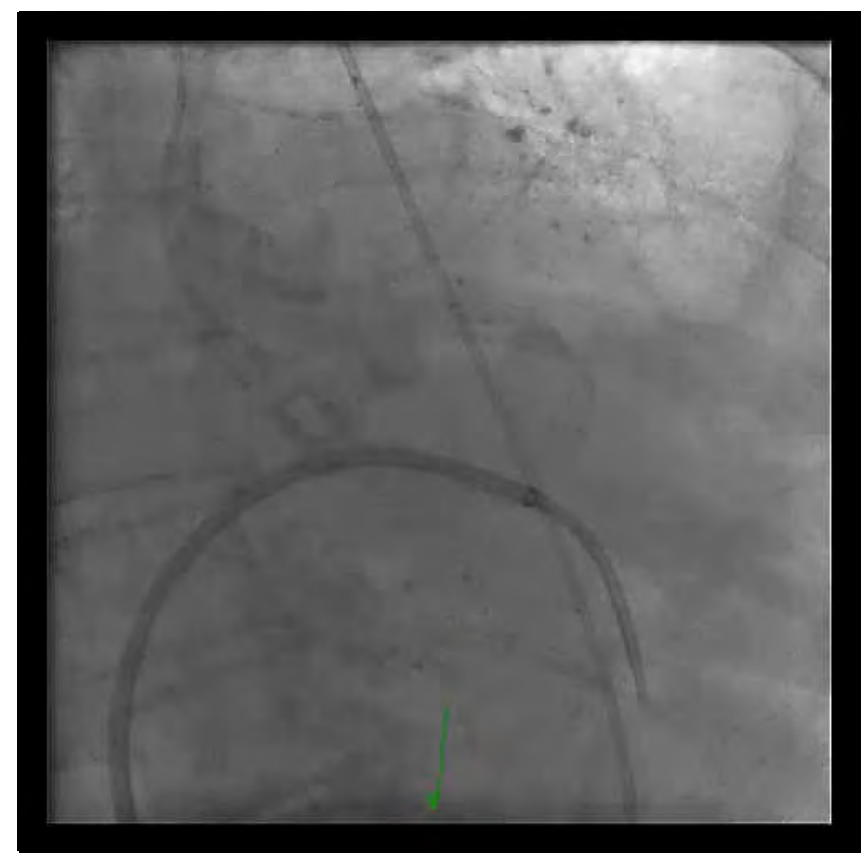

\section{Figure 5 Video.}




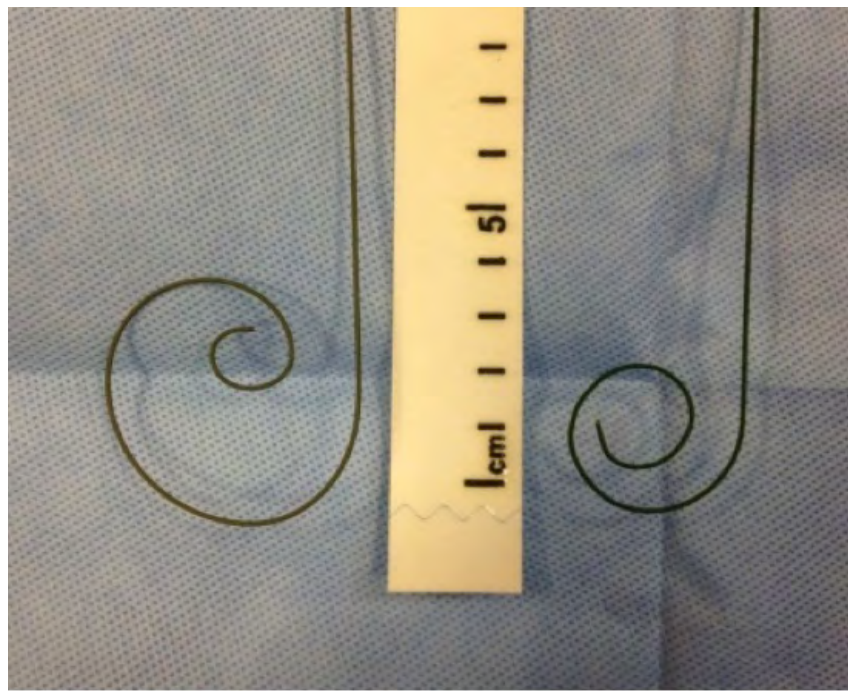

Figure 6. A standard $0.035^{\prime \prime}$ J-tip wire can be introduced into the single-lumen balloon catheter with a large curve added, so that the balloon catheter can be directed around the left ventricular apex.

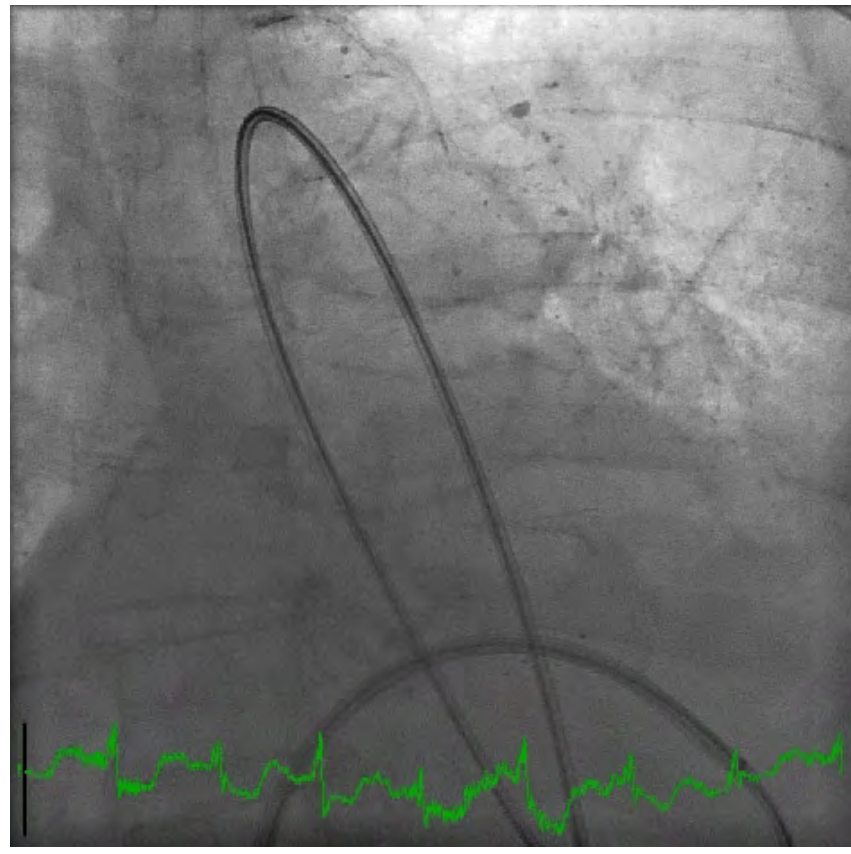

Figure 7. An exchange length 0.032 inch extra stiff wire is passed through the balloon catheter into the descending aorta above the aortic bifurcation.

have improved significantly. In addition to technology improvements, several key advances in the technique have made it more successful. Particularly, the

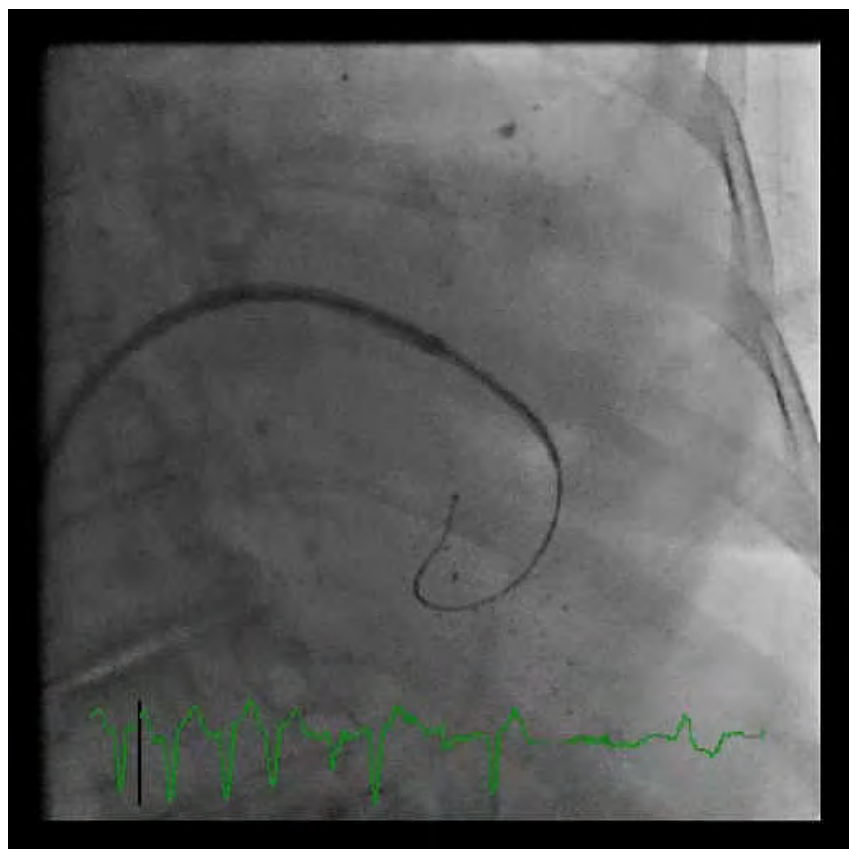

Figure 6 Video.

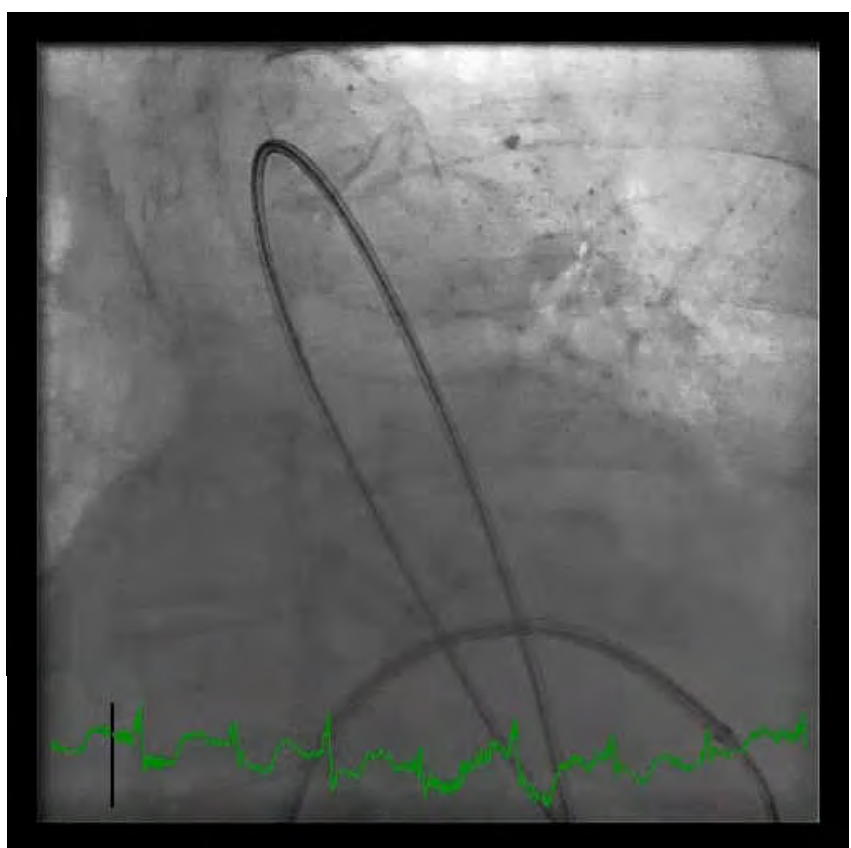

Figure 7 Video.

advent of rapid right ventricular pacing during balloon inflations to minimize balloon movement or "watermelon seeding" has made the procedure much 
more manageable. The basic technique involves obtaining femoral arterial access, performing suture preclosure, and placing an arterial sheath ranging in diameter from 10 up to 14 French, depending on the balloon type and size. Meticulous technique using fluoro- or ultrasound-guided femoral access to ensure sheath insertion in a non-calcified segment of the common femoral artery is critical (Figure 2). After access is obtained, the valve is crossed using standard techniques (Figure 3) and stiff exchange wire is placed as a rail for delivery of the balloon. The balloon is advanced retrograde over the guidewire into the left ventricle and positioned across the native aortic valve annulus. Rapid pacing at a heart rate, typically between 170 and 200 beats per minute is initiated and when the blood pressure falls, the balloon is inflated (Figure 4). After full inflation is achieved, the balloon is withdrawn and rapid pacing discontinued. If the balloon was ejected from the ventricle during the inflation, and blood pressure recovery has been adequate, a second inflation may be performed. At that point, the result is assessed and if appropriate to the situation, a larger balloon can be used when the result does not meet the planned expectations. The balloon and wire are withdrawn, and the existing suture is used to close the arterial sheath insertion site, usually with a wire left in place so that if the preclosure fail, an additional Perclose device can be used or a sheath inserted so that manual compression may be undertaken when the anticoagulation normalizes or is reversed. Careful attention to the hemodynamics before and after each inflation is crucial. While it is not necessary to re-measure the transaortic gradient after each inflation it is critical to carefully assess the changes in aortic diastolic pressure as an indicator of increase aortic insufficiency. If a second inflation is necessary, the possibility of more than mild aortic insufficiency should be excluded before proceeding for the second attempt.

\section{Antegrade BAV}

A much less utilized approach is to deliver a balloon into the native aortic annulus using transvenous-trans-septal access [11]. From the trans-septal puncture into the left atrium, a single-lumen balloon catheter can be floated into the left ventricle

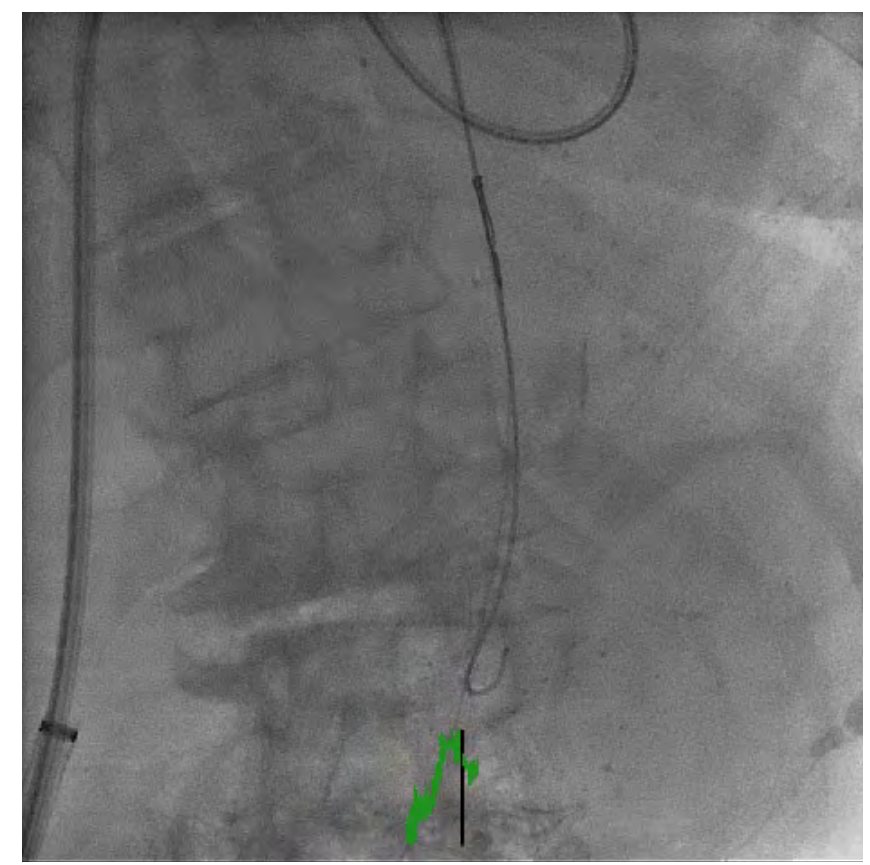

Figure 8. The left femoral artery access can be used to introduce a $10 \mathrm{~mm}$ gooseneck snare to catch the distal end of the 0.032 inch wire.

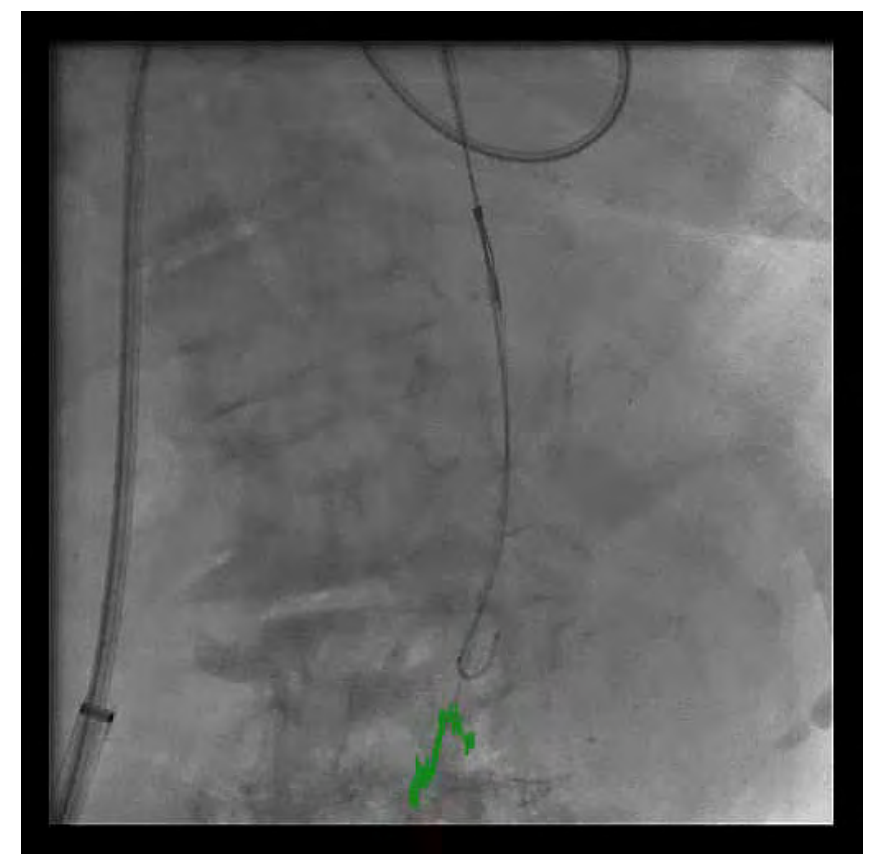

Figure 8 Video.

and then into the aorta. This allows delivery of a stiff wire antegrade so that the balloon for BAV may be 


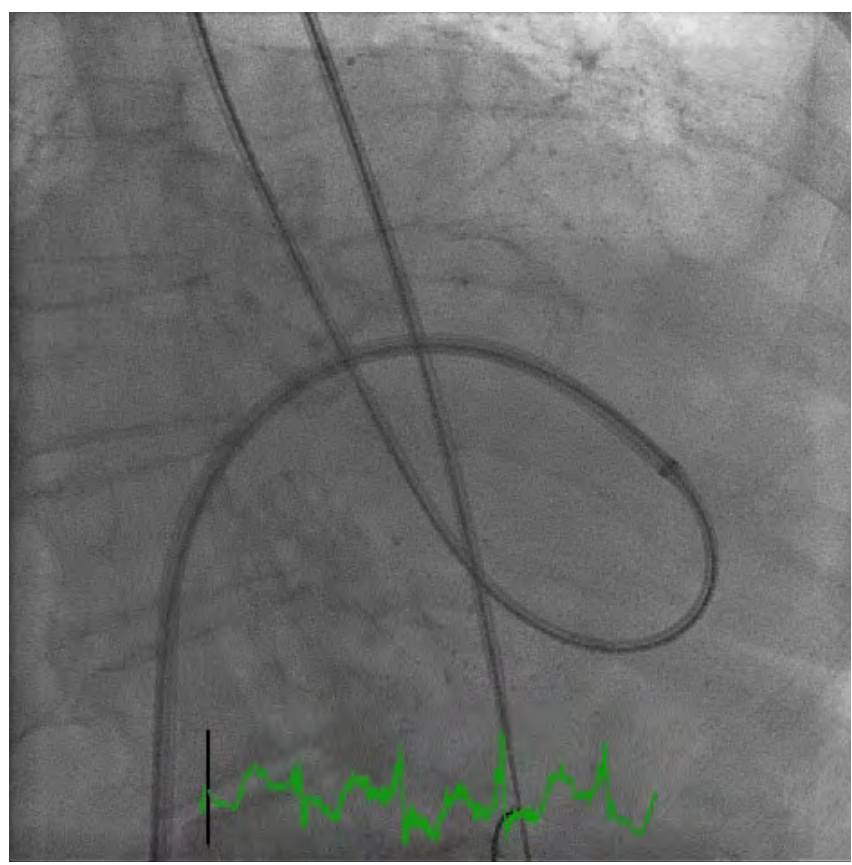

Figure 9. The snared support wire may be left parked in the descending aorta, as this will provide adequate support for antegrade balloon passage.

introduced on the venous side of the circulation and tracked through the left atrium and left ventricle to straddle the aortic valve. Antegrade BAV is technically more demanding than retrograde BAV. Many of the procedure steps are unfamiliar to many BAV and TAVR operators. One of the advantages of antegrade BAV is utilization of a vein rather than an artery for access. This is occasionally useful in patients with severe peripheral arterial disease. Another advantage is stability of the balloon during inflation in the aortic valve even without rapid pacing. Since there is an arterial-venous loop, the balloon can be controlled from both antegrade and retrograde directions and is highly stable. In addition, the use of venous access allows for the utilization of much larger diameter balloons. In our series, this resulted in larger acute valve areas BAV compared to a retrograde technique.

The next several paragraphs will detail the specific procedure steps of antegrade BAV. The initial set up for antegrade BAV includes 7 French left femoral arterial and 7 or 8 French left femoral venous access, and for the trans-septal puncture, 14 French right femoral venous access. The arterial access sheath size is required to place a $10 \mathrm{~mm}$ gooseneck snare via the left

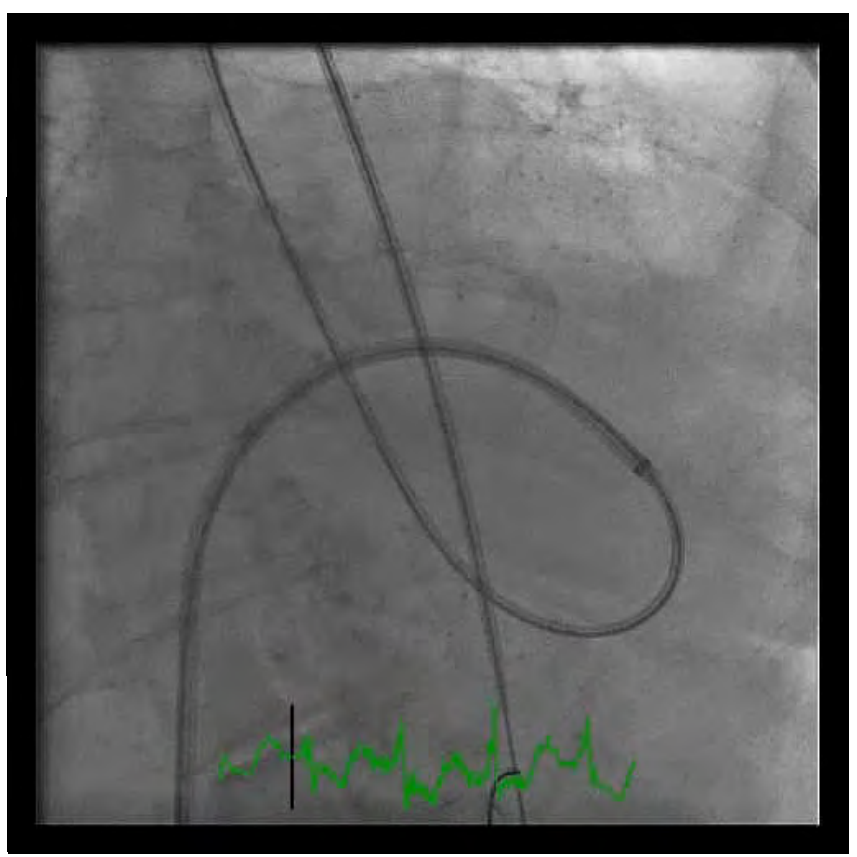

Figure 9 Video.

femoral arterial sheath and still have enough room for arterial pressure measurement. The left femoral venous access is for initially pulmonary artery catheterization and cardiac output measurement, and subsequently for medication administration if needed. The 14 French right femoral venous access facilitates trans-septal puncture and allows for placement of a Inoue balloon catheter.

After access is obtained, trans-septal puncture is performed. A posterior mid fossa level puncture allows easiest access to the mitral orifice. A 7 French single-lumen balloon catheter is inflated in the left atrium and with counterclockwise rotation of a standard Mullins sheath the balloon tip catheter is floated across the mitral valve (Figure 5). At this point, the transaortic valve pressure gradient can be measured. A standard 0.035 " J-tip wire can be introduced into the single-lumen balloon catheter with a large curve added, so that the balloon catheter can be directed around the left ventricular apex (Figure 6). At this point, it is sometimes necessary to switch to a floppy tip straight wire such as a Wholey wire to cross the aortic valve antegrade and with the single-lumen catheter balloon deflated, pass the balloon catheter 


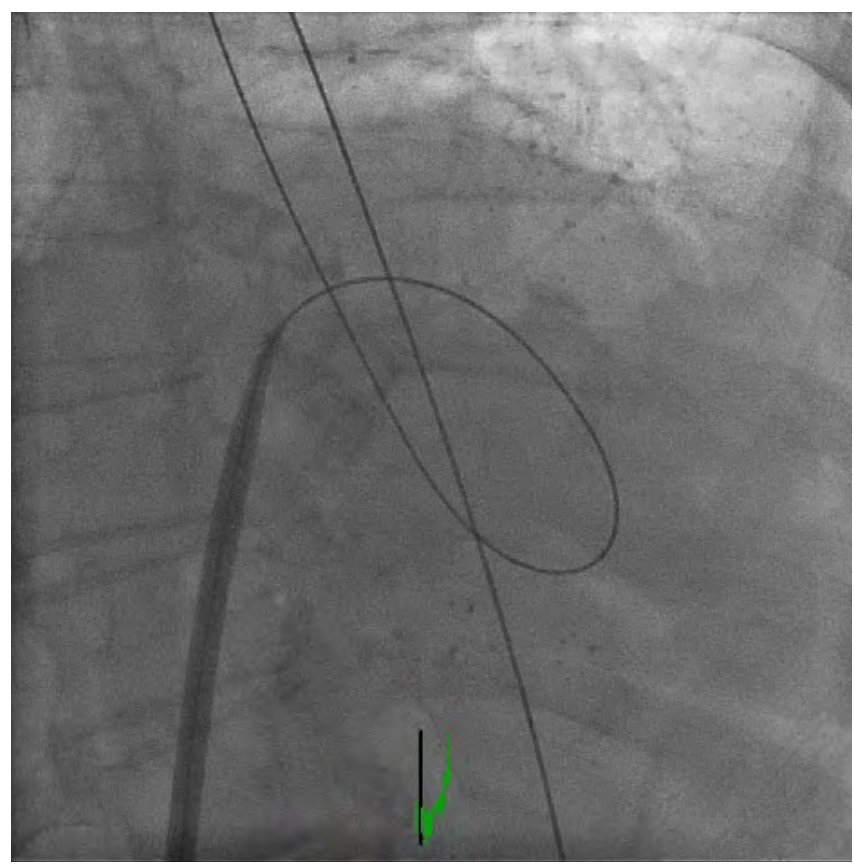

Figure 10. Dilation of the interatrial septum.

into the aortic root. The balloon catheter is then maneuvered with a wire into the descending aorta. At this point, an exchange length 0.032 inch extra stiff wire is passed through the balloon catheter into the descending aorta above the aortic bifurcation (Figure 7). The left femoral artery access can be used to introduce a $10-\mathrm{mm}$ gooseneck snare to catch the distal end of the 0.032-inch wire (Figure 8). While it is possible to exteriorize the arteriovenous loop, there is no need for this and the snared support wire may be left parked in the descending aorta, as this will provide adequate support for antegrade balloon passage (Figure 9).

The Mullins sheath and single-lumen balloon catheter are then withdrawn through the 14 French right femoral venous sheath exchanged for Inoue balloon 14 French dilator. The septum is dilated (Figure 10). The Inoue balloon is prepped. The Inoue balloon is then introduced in itstretched configuration. In the United States, the smallest available balloon is the maximum recommended inflated diameter of 26 $\mathrm{mm}$. For most women, a single balloon inflation of 24 or $25 \mathrm{~mm}$ can be performed. For most men, a single inflation of 25 or $26 \mathrm{~mm}$, using the calibrated inflation

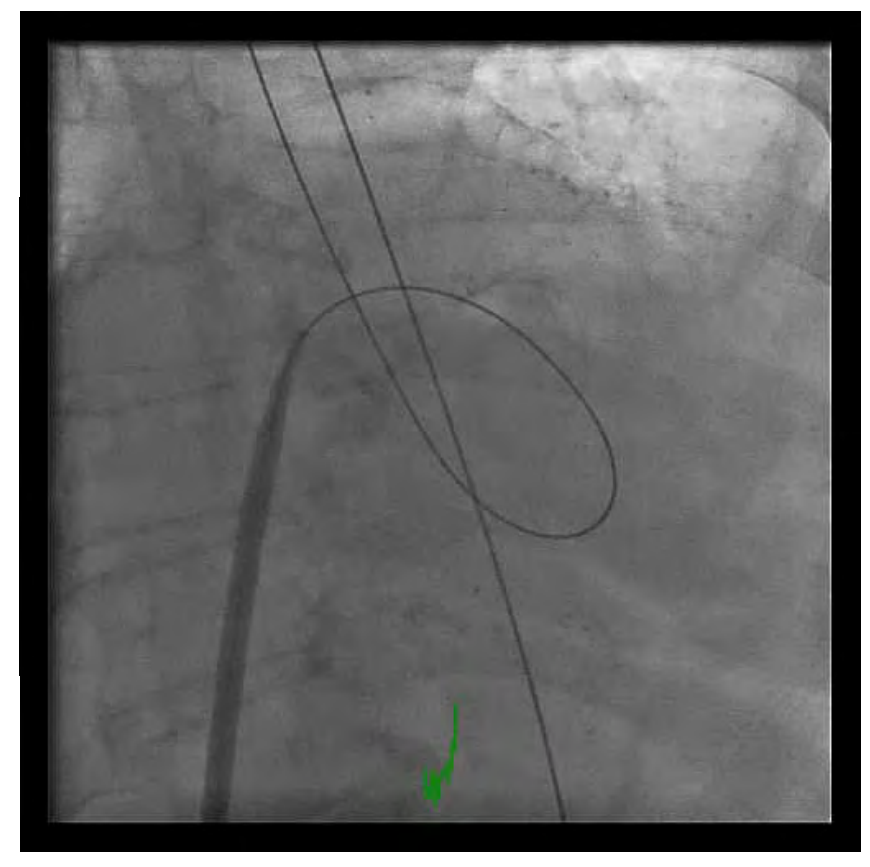

Figure 10 Video.

syringe, is adequate.

The stretched balloon is introduced into the left atrium, and then unstretched. The balloon is tracked around the arteriovenous loop through the mitral valve and into the aortic valve. It sometimes requires pushing from the venous side and pulling on the arterial side to get the balloon into position in the native aortic valve. Without any need for rapid pacing, the balloon is inflated in its usual stepwise fashion (Figure 11). The distal part of the balloon was inflated on the arch side of the aortic valve and pulled back to engage the valve and then the balloon is fully inflated. A rapid inflate-deflate is important. It is also important, as soon as the balloon deflated, to back it out of the aortic valve into the left atrium, and to re-establish the arteriovenous loop so that there is no tension on the mitral valve leaflets.

In some cases, progressive hypotension begins as soon as the arteriovenous loop is introduced and the procedure must be aborted. In other cases, the onset of this mitral regurgitation related hypotension is gradual and if the procedure can be accomplished rapidly, the arteriovenous loop can be decompressed or removed before significant hypotension occurs. 


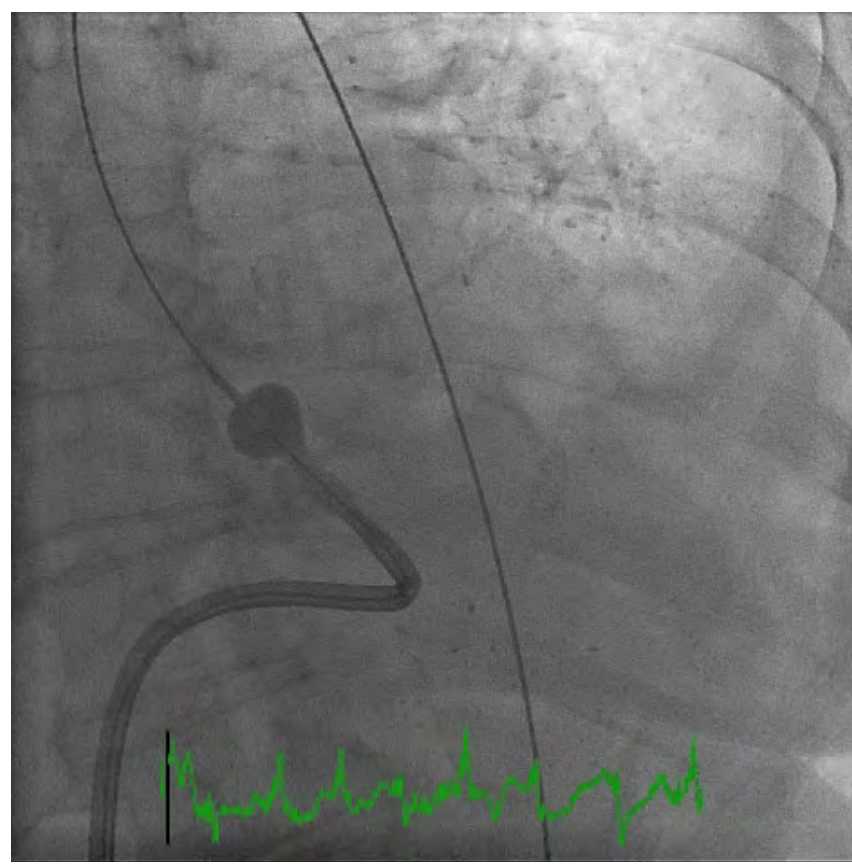

Figure 11. The balloon is inflated in stepwise fashion without any need for rapid pacing.

Unlike the case in retrograde BAV, the Inoue balloon completely occludes the aortic outflow and this is often poorly tolerated by the left ventricle. Episodes of slow pressure recovery with the antegrade technique are more common than with the retrograde technique. It is my practice to have both atropine and epinephrine or phenylephrine open and available for this possibility. Epinephrine or phenylephrine doses of 50 up to $250 \mu \mathrm{g}$ are usually sufficient without causing rebound hypertension.

After the balloon catheter has been pulled back into the left atrium it can be stretched and removed over the wire. At this point, it is critical to place a diagnostic catheter from the venous side over the 0.032 inch wire and pass this catheter across the mitral and aortic valves and into the aorta. The gooseneck snare can be removed, and then the exchange wire pulled back into the diagnostic catheter. $A$ pigtail is best used for this purpose, as the pigtail is pulled back it can be left in the left ventricle. This is easier if the Mullins sheath is introduced over the wire before the pigtail is placed. A post intervention gradient can be assessed to determine the results of the procedure. Covering the arteriovenous loop wire with a diagnostic catheter before removing the wire is critical, since

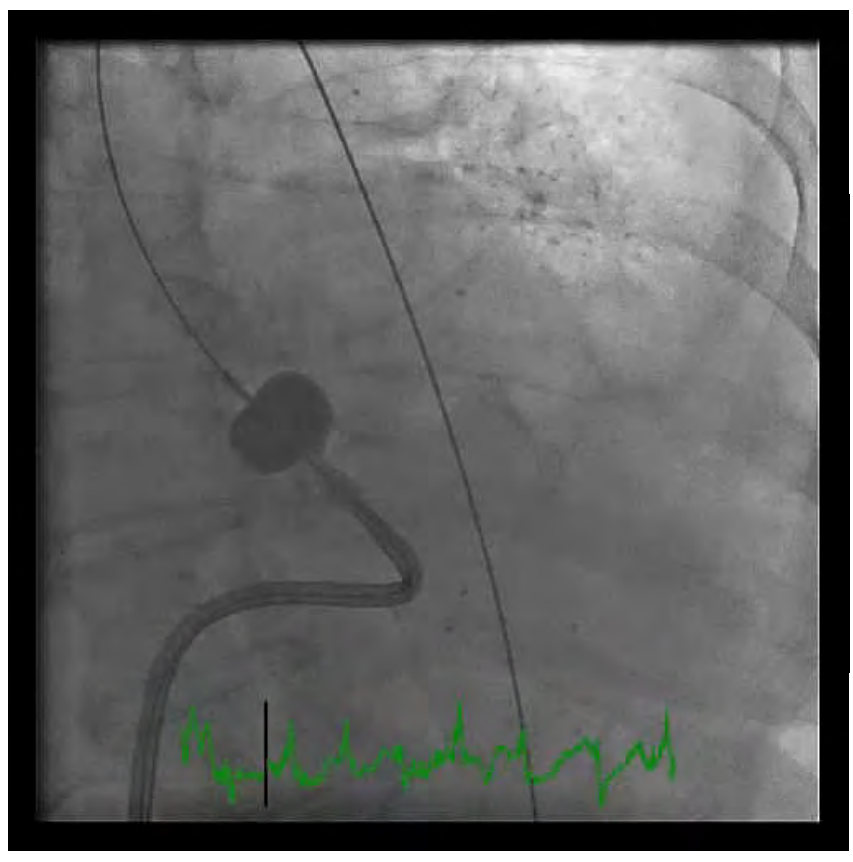

Figure 11 Video.

the wire can "cheese cut" the mitral valve if it is pulled back without protecting the valve.

\section{Future Perspectives in Aortic Valvuloplasty Technologies}

Most of the current balloons in use for aortic valvuloplasty were not specifically designed for this purpose and thus have limitations. They have predominantly been peripheral angioplasty balloons which are cylindrical in shape, with a spectrum of balloon diameter lengths and compliance characteristics. Until recently, none of these have been FDA approved for the BAV indication. The re-emergence of "stand-alone" BAV, TAVR pre- and post-dilations have led to balloon innovations. One such balloon is the True Dilation Balloon Valvuloplasty Catheter (C. R. Bard, Inc., Tempe, Arizona, USA). This balloon is cylindrical in shape. The balloon matrix is embedded with high-strength fibers rendering the balloon noncompliant and thus achieving precise diameters when inflated. In addition, the shaft size is approximately $10 \mathrm{Fr}$ to permit larger inflation lumens and thus faster inflation and deflation times. Rapid right ventricular pacing is still 


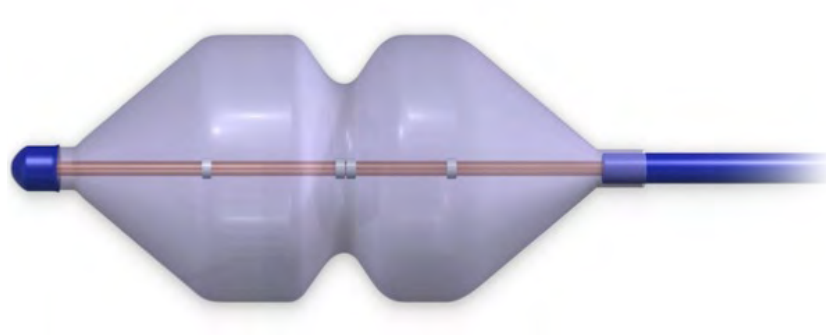

Figure 12. The Intervalve V8 balloon has a geometric "hourglass" configuration designed to take advantage of the complex aortic valve and adjacent anatomy.

recommended to minimize balloon slippage.

A second novel aortic valvuloplasty balloon, the V8 (Intervalve, Inc., Plymouth, Minnesota, USA) has a geometric (i.e., "hourglass") configuration designed to take advantage of the complex aortic valve and adjacent anatomy (Figure 12). Intended benefits include: 1) precise balloon position with stable fixation with or without rapid pacing, 2) greater resultant aortic valve areas due to hyperextension of the valve leaflets into the sinuses of Valsalva by the proximal bulb, and 3) enhanced safety with the retention of a narrower balloon waist, reducing the likelihood of annular rupture. In a propensity-matched study with 40 patients, the delta increase in AVA by echocardiography for the $\mathrm{V} 8$ balloon was $0.30 \pm 0.23 \mathrm{~cm}^{2}$ vs. $0.17 \pm$ $0.21 \mathrm{~cm}^{2}$ for standard cylindrical balloons $(P=0.063)$. There was no severe Al, new IVCD's, or need for PPM's. There were no major adverse events in the V8 group defined as procedure-related death, stroke or emergency surgery [12]. As per direct communication with Intervalve, in over 400 cases procedural mortality was less than $0.5 \%$. The V8 has a $10 \mathrm{Fr}$ shaft and permits rapid inflation/deflation times. A subsequent iteration in development has a radio-opaque ring on the balloon waist to assist in establishing co-planarity with the target AV annulus for TAVR positioning.

A third novel valvuloplasty balloon, the Valvulosculpt Balloon (Angioscore, Fremont, California, USA) is cylindrical in shape and has a helical wire lattice on the exterior balloon surface to enhance fixation and potentially augment AVA by proposed leaflet scoring. This balloon is in early phase testing and not yet FDA approved. It has been related to the authors by direct communication with Angioscore that fur-

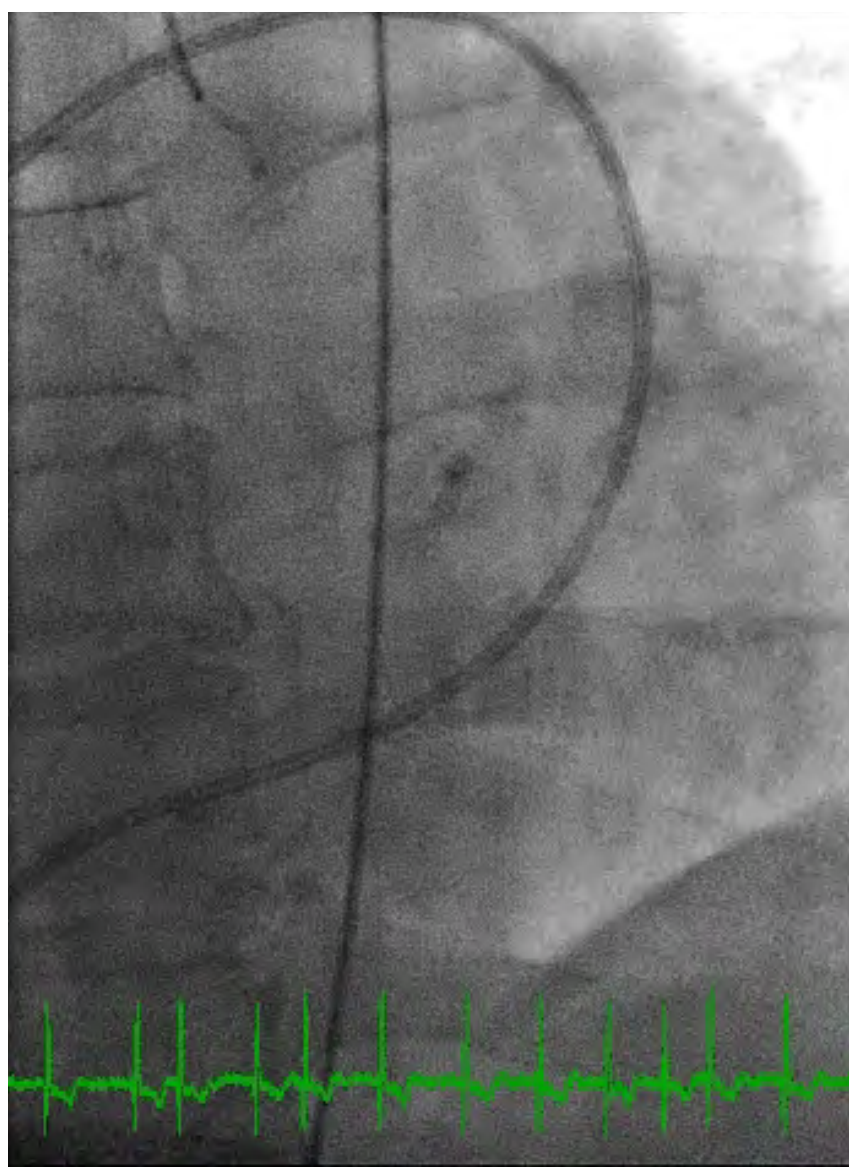

Figure 13. Pre-shaped, extra stiff, guide wires including the "Safari" wire (left-Boston Scientific, Plymouth, MN) and "Confida" (right-Medtronic, Minneapolis, MN) have recently been brought to market for TAVR as well as BAV.

ther testing with the intention of coming to market has been frozen.

Finally, catheter-based concepts for calcific valve leaflet remodeling have been proposed. Energy sources for consideration include high-frequency ultrasound, with application of the lithotripsy, and transmission of vibration through direct catheter-to-leaflet contact with a mechanical device.

Pre-shaped, extra stiff, guide wires including the "Safari" wire (Boston Scientific, Plymouth, Minnesota, USA) and "Confida" (Medtronic, Minneapolis, Minnesota, USA) have recently been brought to market for TAVR as well as BAV (Figure 13, Safari left \& Confida right). These new wires offer better straightening of tortuous vascular anatomy and large distal curves with smooth transitions in the LV. These features enhance greater wire stability and support as well as a 
diminished likelihood of LV perforation.

\section{Complications}

BAV may cause clinically important complications, mainly during the procedure that should be addressed immediately. The main complications include death $(2.5 \%)$, stroke $(2 \%)$, vascular complications $(2.5 \%)$, severe aortic insufficiency $(1.5 \%)$ and permanent pacemaker requirement $(<1 \%)$ [13]. These risks should be carefully addressed to the patients prior to the procedures. Severe aortic insufficiency is more common with balloon oversizing. A strategy for the short term management of severe aortic insufficiency is tachycardia pacing [14]. In the worst cases a permanent pacemaker can be implanted and used to keep the heart rate between 90-110 bpm to minimize the diastolic time. It is noteworthy that high volume operators may have a lower incidence of these complications. Also, the studies are somewhat heterogeneous, and the risk of the patients may vary from one study to the other. For example, in one study the investigators included patients with cardiogenic shock who underwent BAV, and the in-hospital mortality was $56 \%$, but the overall risk of patients without cardiogenic shock was still $2 \%$ [15]. This emphasizes the underlying risk inherent in the patients that undergo $\mathrm{BAV}$, and the importance of careful patient selection for the procedure.

\section{Conclusions}

BAV has had resurgence in association with the dissemination of TAVR. The lack of clear mortality benefit from BAV does not translate to lack of efficacy as a palliative therapy. BAV remains useful a bridge to surgical AVR or TAVR, and for symptom relief in patients who not candidates for either AVR approach. It is also useful as a diagnostic test for patients with low gradient-low output AS, and for those with mixed pulmonary and aortic valvular disease. BAV is used commonly for TAVR predilatation, and this is sometimes helpful for annulus size assessment. Careful attention to balloon diameter selection and the details of technique are important for optimizing outcomes.

\section{Conflict of Interest}

Dr Feldman is a consultant to Abbott, BSC, and Edwards. Dr Pedersen has ownership interest in InterValve.

\section{Comment on this Article or Ask a Question}

\section{References}

1. Agarwal A, Kini AS, Attanti S, Lee PC, Ashtiani R, Steinheimer AM, et al. Results of repeat balloon valvuloplasty for treatment of aortic stenosis in patients aged 59 to 104 years. Am J Cardiol. 2005;95:43-47. DOI: 10.1016/j.amjcard.2004.08.061

2. Hara $H$, Pedersen WR, Ladich E, Mooney $M$, Virmani $R$, Nakamura $M$, et al. Percutaneous balloon aortic valvuloplasty revisited: time for a renaissance? Circulation. 2007;115:e334-e338. DOI: 10.1161/CIRCULATIONAHA.106.657098

3. Pedersen WR, Goldenberg IF, Feldman T. BAV in the TAVI Era: A review of current technique; uses in stand alone, bridging and predilation settings. Card Interv Today. 2010;4(4):77-84. Retrieved from http://citoday.com/2010/08/balloon-aortic-valvuloplasty-in-the-tavi-era/
4. Nishimura RA, Otto $C M$, Bonow RO, Carabello BA, Erwin JP III, Guyton RA, et al. 2014 AHA/ ACC guideline for the management of patients with valvular heart disease: $\mathrm{A}$ report of the American College of Cardiology/American Heart Association Task Force on Practice Guidelines. J Am Coll Cardiol. 2014;63:e57-185. DOI: 10.1016/j. jacc.2014.02.536

5. Saia F, Marrozzini C, Moretti C, Ciuca C, Taglieri N, Bordoni B, et al. The role of percutaneous balloon aortic valvuloplasty as a bridge for transcatheter aortic valve implantation. Eurolntervention. 2011;7(6):723-729. DOI: 10.4244/EIJV7I6A 115

6. Ussia GP, Capodanno D, Barbanti M, Scarabelli M, Imme S, Cammalleri V, et al. Balloon aortic valvuloplasty for severe aortic ste- nosis as a bridge to high-risk transcatheter aortic valve implantation. J Invasive Cardiol. 2010;22(4):161-166. PMID: 20351386

7. Kristensen SD, Knuuti J, Saraste A, Anker S, Bøtker HE, Hert SD, et al. 2014 ESC/ ESA Guidelines on non-cardiac surgery: cardiovascular assessment and management: The Joint Task Force on non-cardiac surgery: cardiovascular assessment and management of the European Society of Cardiology (ESC) and the European Society of Anaesthesiology (ESA). Eur Heart J. 2014;35(35):2383-2431. DOI: 10.1093/eurheartj/ehu282

8. Patsalis PC, Al-Rashid F, Neumann T, Plicht B, Hildebrandt HA, Wendt D, et al. Preparatory balloon aortic valvuloplasty during transcatheter aortic valve implantation for improved valve sizing. JACC Cardiovasc 
Interv. 2013;6(9):965-971. Erratum in: JACC Cardiovasc Interv. 2013 Oct;6(10):1110. DOI: 10.1016/j.jcin.2013.05.006

9. Barbanti $M$, Sgroi $C$, Immè $S$, Aruta $P$, Deste W, Gulino S, et al. Usefulness of contrast injection during balloon aortic valvuloplasty before transcatheter aortic valve replacement: A pilot study. Eurolntervention. 2014;10(2):241-7. DOI: 10.4244/ElJV1012A39

10. Feldman T, Nguyen TN. Retrograde percutaneous aortic valvuloplasty (Chapter 19). In: Nguyen T, Hu D, Chen SL, Kim MH, Saito S, Grines C, Gibson CM, Bailey SR. Practical Handbook of Advanced Interventional Cardiology: Tips and Tricks, 4th Edition. UK: Wiley-Blackwell; 2013, p.475-486. DOI: 10.1002/9781118592380.ch19

11. Pedersen WR, Mooney MR, Ungs D, Pedersen C, Sorajja P, Poulose AK, et al. Improvement in aortic valve area using a new "hour glass" shaped valvuloplasty balloon com- pared with standard cylindrical balloons in severe aortic stenosis patients. Minerva Cardioangiologica. 2014(62):243-249. PMID: 24831760

12. Sakata Y, Sayed Z, Salinger MH, Feldman T. Percutaneous balloon aortic valvuloplasty: Antegrade transseptal vs. conventional retrograde transarterial approach. Cathet Cardiovasc Intervent. 2005;64:314-321. DOI: $10.1002 / \mathrm{ccd} .20300$

13. Eltchaninoff $H$, Durand $E$, Borz $B$, Furuta $A$, Bejar K, Canville A, et al. Balloon aortic valvuloplasty in the era of transcatheter aortic valve replacement: Acute and long-term outcomes. Am Heart J. 2014;167(2):235240. DOI: 10.1016/j.ahj.2013.10.019

14. Ali O, Salinger MH, Levisay JP, Feldman T. High pacing rates for management of aortic insufficiency after balloon aortic valvuloplasty or transcatheter aortic valve replacement. Cathet Cardiovasc Intervent. 2014;83:162-168. DOI: 10.1002/ccd.24902
15. Saia F, Marrozzini C, Ciuca C, Guastaroba $\mathrm{P}$, Taglieri N, Palmerini T, et al. Emerging indications, in-hospital and long-term outcome of balloon aortic valvuloplasty in the transcatheter aortic valve implantation era. Eurolntervention. 2013;8(12):13881397. DOI: $10.4244 /$ EIJV8I12A212

Cite this article as: Feldman T, Sarraf M, Pedersen W. Balloon Aortic Valvuloplasty: Patient selection and technical considerations. Structural Heart Disease 2015; 1(1): 20-32. DOI: http://dx.doi. org/10.12945/j.jshd.2015.00009-14 